University of Wollongong

Research Online

Faculty of Engineering - Papers (Archive)

Faculty of Engineering and Information

Sciences

2006

\title{
Enhancement of in-field Jc in MgB2 /Fe wire using single- and multiwalled carbon nanotubes
}

J. H. Kim

University of Wollongong, jhk@uow.edu.au

W. K. Yeoh

University of Wollongong

M. J. Qin

University of Wollongong, qin@uow.edu.au

X. Xu

University of Wollongong

S. X. Dou

University of Wollongong, shi@uow.edu.au

Follow this and additional works at: https://ro.uow.edu.au/engpapers

Part of the Engineering Commons

https://ro.uow.edu.au/engpapers/461

\section{Recommended Citation}

Kim, J. H.; Yeoh, W. K.; Qin, M. J.; Xu, X.; and Dou, S. X.: Enhancement of in-field Jc in MgB2 /Fe wire using single- and multiwalled carbon nanotubes 2006.

https://ro.uow.edu.au/engpapers/461

Research Online is the open access institutional repository for the University of Wollongong. For further information contact the UOW Library: research-pubs@uow.edu.au 


\title{
Enhancement of in-field $J_{c}$ in $\mathrm{MgB}_{2} / \mathrm{Fe}$ wire using single- and multiwalled carbon nanotubes
}

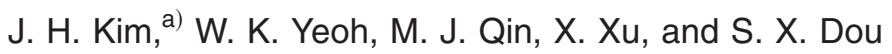 \\ Institute for Superconducting and Electronic Materials, University of Wollongong, Northfields Avenue, \\ Wollongong, New South Wales 2522, Australia \\ P. Munroe \\ Electron Microscopy Unit, University of New South Wales, Kensington, Sydney, New South Wales 2052, \\ Australia \\ H. Kumakura, T. Nakane, and C. H. Jiang \\ Superconducting Materials Center, National Institute for Materials Science, 1-2-1, Sengen, Tsukuba, Ibaraki \\ 305-0047, Japan
}

(Received 9 March 2006; accepted 5 August 2006; published online 19 September 2006)

\begin{abstract}
The authors investigated the doping effects of single-walled carbon nanotubes (SWCNTs) and multi-walled carbon nanotubes (MWCNTs) on the $T_{c}$, lattice parameters, $J_{c}(B)$, microstructure, and $H_{c 2}$ of $\mathrm{MgB}_{2} / \mathrm{Fe}$ wire. These effects systematically showed the following sequence for $T_{c}$ and the $a$ axis: the SWCNT doped wire $<$ the $\mathrm{MW}_{\text {short }} \mathrm{CNT}$ doped wire $<$ the $\mathrm{MW}_{\text {long }} \mathrm{CNT}$ doped wire $<$ undoped wire, while $J_{c}(B)$ followed the sequence of the SWCNT doped wire $>$ the $\mathrm{MW}_{\text {short }} \mathrm{CNT}$ doped wire $>$ the $\mathrm{MW}_{\text {long }} \mathrm{CNT}$ doped wire $>$ undoped wire. A dominating mechanism behind all these findings is the level of $\mathrm{C}$ substitution for B in the lattice. () 2006 American Institute of Physics. [DOI: 10.1063/1.2355467]
\end{abstract}

The effects of carbon (C) doping on superconducting properties in $\mathrm{MgB}_{2}$ compound have been studied by a number of groups. ${ }^{1-6}$ From the applications point of view, the effect of $\mathrm{C}$ doping on the flux pinning properties and upper critical field $\left(H_{c 2}\right)$ is crucially important. Recently, several groups have reported a significant improvement in critical current density $\left(J_{c}\right), H_{c 2}$, and irreversibility field $\left(H_{\text {irr }}\right)$ in $\mathrm{MgB}_{2}$ through $\mathrm{C}$ doping in various forms, including $\mathrm{C}, \mathrm{SiC}$, carbon nanotube $(\mathrm{CNT})$, and $\mathrm{B}_{4} \mathrm{C} .^{7-10}$ Among various $\mathrm{C}$ precursors, CNTs are particularly interesting as their special geometry may induce more effective pinning centers compared to other C-containing precursors. Furthermore, CNTs have unusual electrical, mechanical, and thermal properties. ${ }^{11}$ These properties could improve the interior thermal stability, heat dissipation, and mechanical strength of $\mathrm{MgB}_{2}$ superconductor wire. The Kim et al. ${ }^{8}$ and Dou et al. ${ }^{12}$ have demonstrated that CNT doping not only resulted in a significant enhancement of in-field $J_{c}$ performance but also improved heat transfer and dissipation. The CNTs are composed of one or more concentric graphene cylinders, which are called single-walled carbon nanotubes (SWCNTs) and multi-walled carbon nanotubes (MWCNTs), respectively. ${ }^{13}$ The fundamental properties of SWCNTs and MWCNTs are different from each other. The effect of different types of CNTs on the superconducting properties of $\mathrm{MgB}_{2}$ remains unclear. Thus, it is necessary to study the effects of the configuration and dimensions of the CNTs on the superconducting properties of $\mathrm{MgB}_{2}$.

$\mathrm{MgB}_{2} / \mathrm{Fe}$ wires were prepared by in situ reaction and the powder-in-tube method. Powders of magnesium ( $\mathrm{Mg}, 99 \%)$, boron (B, 99\%), and SWCNT/MWCNTs were used as starting materials. These powders were well mixed with a starting composition of $\mathrm{MgB}_{1.8} \mathrm{C}_{0.2}$, because this composition re-

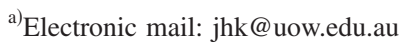

sulted in the highest $J_{c}$ in our group of samples. ${ }^{8}$ Two different MWCNT batches had two different average aspect ratios and are hereafter called $\mathrm{MW}_{\text {short }} \mathrm{CNT}$ and $\mathrm{MW}_{\text {long }} \mathrm{CNT}$, respectively, referring to the length of the CNTs. The specifications of the CNTs are listed in Table I. The mixed powders were packed into iron $(\mathrm{Fe})$ tubes, and then the composites were drawn to an outer diameter of $1.42 \mathrm{~mm}$. These wires were then sintered at $800-1000{ }^{\circ} \mathrm{C}$ for 30 min under high purity argon. Undoped $\mathrm{MgB}_{2} / \mathrm{Fe}$ wire was also fabricated for reference and comparison by applying the same process. All samples were characterized by critical current $\left(I_{c}\right)$, critical temperature $\left(T_{c}\right), H_{c 2}$, x-ray diffraction (XRD), and transmission electron microscopy (TEM) ${ }^{8}$ The lattice parameters were obtained from Rietveld refinement.

Figure 1 shows the $T_{c}$ for all CNT doped and undoped $\mathrm{MgB}_{2} / \mathrm{Fe}$ wires as a function of sintering temperature. It should be noted that for $\mathrm{MW}_{\text {short }} \mathrm{CNT}$ and SWCNT doped wires, $T_{c}$ decreased systematically as the sintering temperature increased, while $T_{c}$ of undoped $\mathrm{MgB}_{2} / \mathrm{Fe}$ wires increased with increasing sintering temperature. It is well established that higher sintering temperature results in better crystallinity and hence higher $T_{c}$. On the other hand, for CNT doped samples, $T_{c}$ is suppressed in proportion to the amount of $C$ substituted in a given sample. ${ }^{7-9}$ Even though the nominal composition remains the same, a higher sintering temperature results in more $\mathrm{C}$ substitution for $\mathrm{B}$. Thus, $T_{c}$

TABLE I. Specifications of $\mathrm{MW}_{\text {short }} \mathrm{CNT}, \mathrm{MW}_{\text {long }} \mathrm{CNT}$, and SWCNT.

\begin{tabular}{cccc}
\hline \hline & $\mathrm{MW}_{\text {short }} \mathrm{CNT}$ & $\mathrm{MW}_{\text {long }} \mathrm{CNT}$ & $\mathrm{SWCNT}$ \\
\hline Purity & $>95 \%$ & $>95 \%$ & $>90 \%$ \\
Outer diameter $(\mathrm{nm})$ & $20-30$ & $<8$ & $1-2$ \\
Length $(\mu \mathrm{m})$ & 0.5 & $0.5-200$ & $5-15$ \\
& & & Amorphous $\mathrm{C}, \mathrm{Mg}$, \\
Impurity components & $\mathrm{Cl}, \mathrm{Fe}$, and $\mathrm{Ni}$ & $\mathrm{Al}, \mathrm{Cl}, \mathrm{Co}$, and $\mathrm{S}$ & $\mathrm{Co}, \mathrm{Mo}$, and $\mathrm{SiO}_{2}$
\end{tabular}

Impurity components $\mathrm{Cl}, \mathrm{Fe}$, and $\mathrm{Ni} \mathrm{Al}, \mathrm{Cl}, \mathrm{Co}$, and $\mathrm{S} \mathrm{Co}$, Mo, and $\mathrm{SiO}_{2}$ 


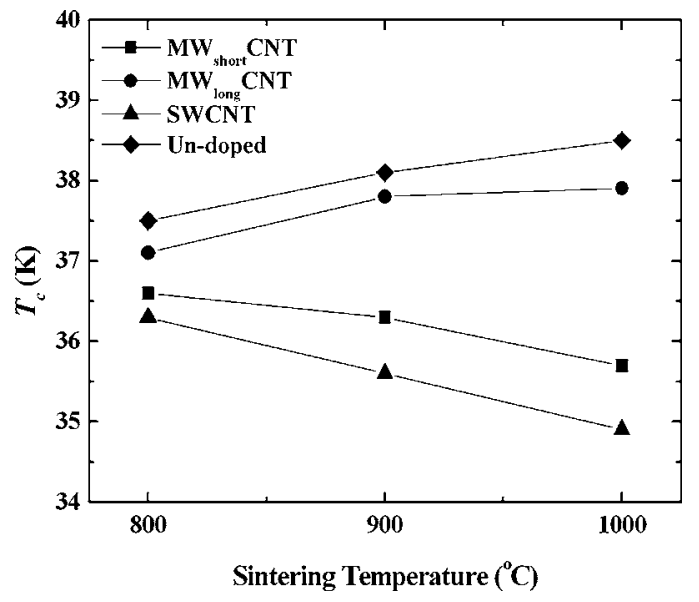

FIG. 1. $T_{c}$ for all CNT doped and undoped $\mathrm{MgB}_{2} / \mathrm{Fe}$ wires as a function of sintering temperature. $T_{c}$ was defined as the onset temperature at which diamagnetic properties were observed.

for the $\mathrm{MW}_{\text {short }} \mathrm{CNT}$ and SWCNT doped wires decreased with increasing sintering temperature. The SWCNT doping showed a stronger depression in $T_{c}$ than the $\mathrm{MW}_{\text {short }} \mathrm{CNT}$ doping, suggesting that SWCNT is more reactive with $\mathrm{MgB}_{2}$ than $\mathrm{MW}_{\text {short }} \mathrm{CNT}$. What is surprising is that the $T_{c}$ for the $\mathrm{MW}_{\text {long }} \mathrm{CNT}$ doped wire showed an opposite trend from the $\mathrm{MW}_{\text {short }} \mathrm{CNT}$ and SWCNT doped wires, but had the same behavior as undoped $\mathrm{MgB}_{2} / \mathrm{Fe}$ wires. These results indicate that the $\mathrm{MW}_{\text {long }} \mathrm{CNTs}$ are the least reactive while the $\mathrm{MW}_{\text {short }} \mathrm{CNTs}$ are more reactive, and the SWCNTs are the most reactive to $\mathrm{MgB}_{2}$.

These observations are further supported by the XRD data, as shown in Table II. Within the limits of calculation error, the $a$ axis lattice parameter for $\mathrm{MW}_{\text {long }} \mathrm{CNT}$ doped $\mathrm{MgB}_{2} / \mathrm{Fe}$ wires showed little change at the sintering temperature of $900{ }^{\circ} \mathrm{C}$ compared with undoped one. In contrast, the $a$ axis parameters for $\mathrm{MW}_{\text {short }} \mathrm{CNT}$ and SWCNT doped wires showed a noticeable decrease compared with the undoped and $\mathrm{MW}_{\text {long }} \mathrm{CNT}$ doped ones. The $c$-axis lattice parameter remained unchanged for all doped samples. This is the typical situation for C substitution in B site as reported previously. ${ }^{2,6}$ Based on the lattice parameter changes ${ }^{14}$ we could quantitatively estimate the amount of $\mathrm{C}$ substituted in $\mathrm{B}$ sites, as shown in Table II. It is evident that the amount of $\mathrm{C}$ substitution for $\mathrm{B}$ is much less than the nominal composition. However, what is worth noting is that more $\mathrm{C}$ is substituted in B sites in the SWCNT and $\mathrm{MW}_{\text {short }} \mathrm{CNT}$ doped wires than the $\mathrm{MW}_{\text {long }} \mathrm{CNT}$ doped ones. As a result, we believe that the differences in the actual substitution with $\mathrm{C}$ for the different CNTs are most likely due to the different reactivity, which is consistent with the results of $T_{c}$ depression.

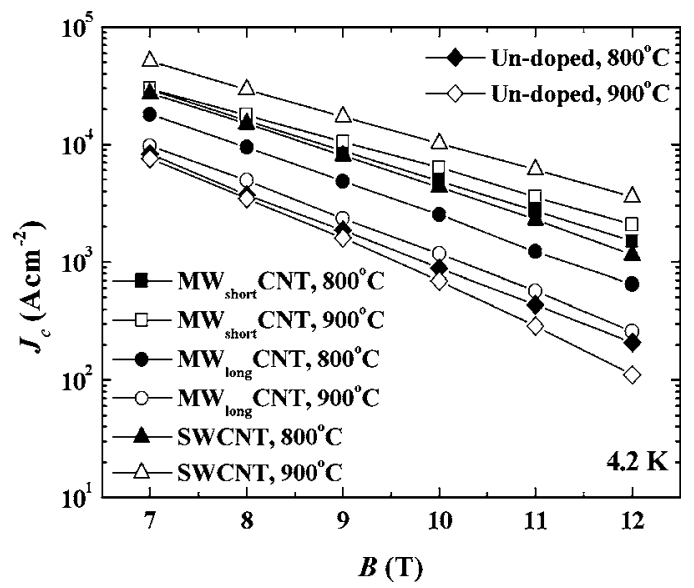

FIG. 2. $J_{c}(B)$ for MWCNT and SWCNT doped $\mathrm{MgB}_{2} / \mathrm{Fe}$ wires sintered at various temperatures for $30 \mathrm{~min}$. $\mathrm{A} J_{c}(B)$ curve of an undoped $\mathrm{MgB}_{2}$ wire is also shown for comparison and reference.

Figure 2 shows the magnetic field dependence of transport $J_{c}$ of all CNT doped and undoped $\mathrm{MgB}_{2} / \mathrm{Fe}$ wires at $4.2 \mathrm{~K}$. It was found that the $J_{c}$ values are spread out by far more than an order of magnitude in the field region measured. For example, the $J_{c}$ values at $4.2 \mathrm{~K}$ and $12 \mathrm{~T}$ for the SWCNT doped wire are higher than that of the undoped wire by a factor of 35 when all were sintered at $900{ }^{\circ} \mathrm{C}$. Of particular interest is that the trend of $J_{c}(B)$ followed the same sequence of change as for $T_{c}$ and the $a$ axis. That is, the SWCNT doped wires showed the best performance in $J_{c}(B)$, and the $\mathrm{MW}_{\text {short }} \mathrm{CNT}$ doped wires were next, while the $\mathrm{MW}_{\text {long }} \mathrm{CNT}$ doped ones had the least improvement in $J_{c}(B)$ compared to the undoped ones. What is more interesting is that in relation to the sintering temperature, the $J_{c}(B)$ for both the $\mathrm{MW}_{\text {short }} \mathrm{CNT}$ and SWCNT doped wires showed an increase with increasing sintering temperature while the $\mathrm{MW}_{\text {long }} \mathrm{CNT}$ doped and undoped wires followed the opposite trend. It has been reported that $\mathrm{C}$ substitution in $\mathrm{B}$ sites can improve the $J_{c}(B), H_{\text {irr }}$, and $H_{c 2}$ but depresses $T_{c}$ for $\mathrm{MgB}_{2}$. The $J_{c}(B)$ of undoped $\mathrm{MgB}_{2} / \mathrm{Fe}$ wire decreased with increasing sintering temperature as a result of further improvement of crystallinity at higher sintering temperature. The $\mathrm{MW}_{\text {long }} \mathrm{CNT}$ doped wires showed the same trend as the undoped ones, suggesting that the level of $\mathrm{C}$ substitution for B did not increase much with increasing sintering temperature. Thus, the improvement of crystallinity dominated the $J_{c}(B)$ behavior in the same way as for as undoped wires.

It is well established that $\mathrm{C}$ substitution into $\mathrm{B}$ sites results in an enhancement in $J_{c}(B)$ and $H_{\text {irr }}$. The temperature dependence of the normalized $H_{c 2}$ for all CNT doped and

TABLE II. Lattice parameters, actual C substitution (Ref. 14) (extrapolation from measured lattice parameters), and resistivities of all $\mathrm{CNT}$ doped and undoped $\mathrm{MgB}_{2} / \mathrm{Fe}$ wires sintered at $900{ }^{\circ} \mathrm{C}$ for 30 min with a starting composition of $\mathrm{MgB}_{1.8} \mathrm{C}_{0.2}$.

\begin{tabular}{|c|c|c|c|c|c|}
\hline \multirow[b]{2}{*}{ Samples } & \multicolumn{3}{|c|}{ Lattice parameters } & \multirow{2}{*}{$\begin{array}{l}\text { Actual C substitution }(x) \\
\text { in } \mathrm{MgB}_{2-x} \mathrm{C}_{x}\end{array}$} & \multirow[b]{2}{*}{$\rho_{40 \mathrm{~K}}(\mu \Omega \mathrm{cm})$} \\
\hline & $a(\AA)$ & $c(\AA)$ & $c / a$ & & \\
\hline Undoped & 3.082 & 3.524 & 1.1434 & & 24.8 \\
\hline $\mathrm{MW}_{\text {short }} \mathrm{CNT}$ & 3.073 & 3.525 & 1.1468 & 0.041 & 57.5 \\
\hline $\mathrm{MW}_{\text {long }} \mathrm{CNT}$ & 3.078 & 3.524 & 1.1449 & 0.018 & 2.60 \\
\hline SWCNT & 3.071 & 3.524 & 1.1475 & 0.050 & 69.7 \\
\hline
\end{tabular}




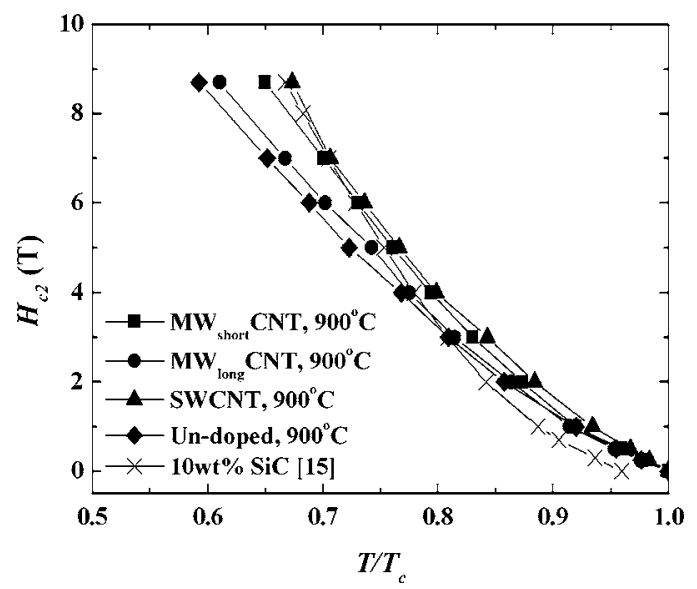

FIG. 3. Temperature dependence of normalized $H_{c 2}$ for all CNT doped and undoped $\mathrm{MgB}_{2} / \mathrm{Fe}$ wires sintered at $900{ }^{\circ} \mathrm{C}$ for $30 \mathrm{~min}$. The $H_{c 2}$ for $10 \mathrm{wt} \% \mathrm{SiC}$ doped $\mathrm{MgB}_{2}$ samples are also shown for comparison (Ref. 15).

undoped $\mathrm{MgB}_{2} / \mathrm{Fe}$ wires sintered at $900{ }^{\circ} \mathrm{C}$ is shown in Fig. 3. The best $H_{c 2}$ was obtained on a SWCNT doped sample, because the slope of $d H_{c 2} / d T$ for the SWCNT sample is larger compared with those for both MWCNTs. This is because SWCNT contributed more C to B sites at high sintering temperature, which is believed to increase the intraband scattering as well as shorten the mean free path and coherence length.

From the $R$ vs $T$ curve (not shown), we also calculated the resistivity $(\rho)$ of the undoped, $\mathrm{MW}_{\text {short }} \mathrm{CNT}$, $\mathrm{MW}_{\text {long }} \mathrm{CNT}$, and SWCNT doped samples sintered at $900{ }^{\circ} \mathrm{C}$, as shown in Table II. It is clear that the SWCNT doped samples showed a relatively higher value of $\rho$ than the $\mathrm{MW}_{\text {short }} \mathrm{CNT}$ doped ones while the undoped one had a lower value of $\rho$. The increased $\rho$ for the SWCNT doped sample could be due to the increased impurity scattering, as it has been shown that substitution of $\mathrm{C}$ for B can result in strong $\sigma$ scattering. ${ }^{16}$ However, the $\mathrm{MW}_{\text {long }} \mathrm{CNT}$ doped sample had a lower $\rho$, compared to the pure sample.

Figure 4 shows TEM images for (a) $\mathrm{MW}_{\text {short }} \mathrm{CNT}$, (b) SWCNT, and (c) $\mathrm{MW}_{\text {long }} \mathrm{CNT}$ doped $\mathrm{MgB}_{2} / \mathrm{Fe}$ wires sintered at $900{ }^{\circ} \mathrm{C}$. The CNTs still existed as $\mathrm{MgB}_{2}-\mathrm{CNT}$ composites after sintering, in particular, for $\mathrm{MW}_{\text {long }} \mathrm{CNT}$ doped sample. These CNTs can contribute to the improvement of thermal and mechanical properties. It is noted that $\mathrm{MW}_{\text {long }} \mathrm{CNTs}$ are well intact and clearly visible after heat treatment [Fig. 4(c)] compared to SWCNTs and $\mathrm{MW}_{\text {short }} \mathrm{CNTs}$. Together with the results on $T_{c}, J_{c}(B)$, and the lattice parameters, it is reasonable to believe that the difference in reactivity of CNTs is attributable to the number of open ends of CNTs.

In summary, SWCNT is an attractive dopant for enhancing $J_{c}$ of $\mathrm{MgB}_{2}$ superconductor in the high field region. The $J_{c}$ in $12 \mathrm{~T}$ and $4.2 \mathrm{~K}$ for the SWCNT doped wire sintered at $900{ }^{\circ} \mathrm{C}$ increased by a factor of 35 compared to that of the undoped wire. The observed $J_{c}(B)$ enhancement in the SWCNT doped sample is attributable to the high level of C substitution into B sites. This demonstrates that $\mathrm{C}$ substitu-

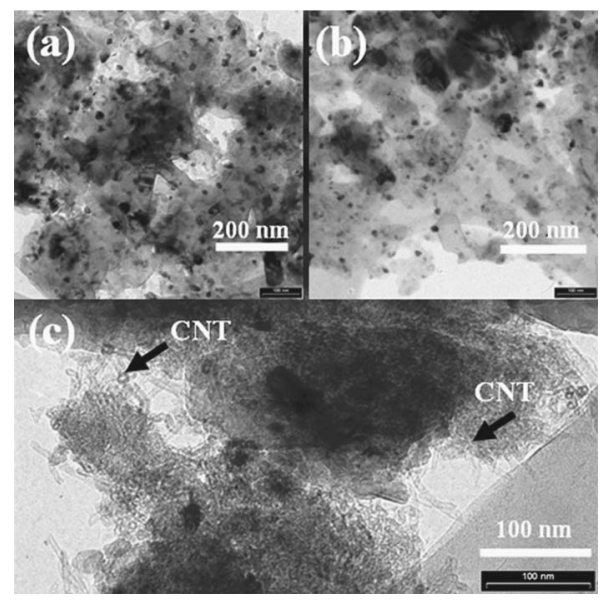

FIG. 4. TEM images for (a) $\mathrm{MW}_{\text {short }} \mathrm{CNT}$, (b) SWCNT, and (c) $\mathrm{MW}_{\text {long }} \mathrm{CNT}$ doped $\mathrm{MgB}_{2} / \mathrm{Fe}$ wires sintered at $900{ }^{\circ} \mathrm{C}$ for 30 min with the nominal composition of $\mathrm{MgB}_{1.8} \mathrm{C}_{0.2}$.

tion for B from dopants is essential for the enhancement of $J_{c}(B)$ and $H_{c 2}$. Doping with $\mathrm{MW}_{\text {long }} \mathrm{CNT}$ has very low level of $\mathrm{C}$ substitution for B and the improvement in $J_{c}$ and $H_{c 2}$ is insignificant.

This work was supported by the Australian Research Council, Hyper Tech Research Inc., USA, Alphatech International Ltd., NZ, and the University of Wollongong.

${ }^{1}$ T. Takenobu, T. Ito, D. H. Chi, K. Prassides, and Y. Iwasa, Phys. Rev. B 64, 134513 (2001).

${ }^{2}$ W. Mickelson, J. Cumings, W. Q. Han, and A. Zettl, Phys. Rev. B 65, 052505 (2002)

${ }^{3}$ Z. H. Cheng, B. G. Shen, J. Zhang, S. Y. Zhang, T. Y. Zhao, and H. W. Zhao, J. Appl. Phys. 91, 7125 (2002).

${ }^{4}$ R. A. Ribeiro, S. Bud'ko, C. Petrovic, and P. C. Canfield, Physica C 382, 166 (2002).

${ }^{5}$ J. Wei, Y. Li, C. Xu, B. Wei, and D. Wu, Mater. Chem. Phys. 78, 785 (2003).

${ }^{6}$ E. Ohmichi, T. Masui, S. Lee, S. Tajima, and T. Osada, J. Phys. Soc. Jpn. 73, 2065 (2004)

${ }^{7}$ S. X. Dou, S. Soltanian, J. Horvat, X. L. Wang, S. H. Zhou, M. Ionescu, H. K. Liu, P. Munroe, and M. Tomsic, Appl. Phys. Lett. 81, 3419 (2002).

${ }^{8}$ J. H. Kim, W. K. Yeoh, M. J. Qin, X. Xu, and S. X. Dou, J. Appl. Phys. 100, 013908 (2006).

${ }^{9}$ R. H. T. Wilke, S. L. Bud'ko, P. C. Canfield, D. K. Finnemore, R. J. Suplinskas, and S. T. Hannahs, Phys. Rev. Lett. 92, 217003 (2004).

${ }^{10}$ Y. Ma, X. Zhang, G. Nishijima, K. Watanabe, S. Awaji, and X. Bai, Appl. Phys. Lett. 88, 072502 (2006).

${ }^{11}$ B. Q. Wei, R. Vajtai, and P. M. Ajayan, Appl. Phys. Lett. 79, 1172 (2001).

${ }^{12}$ S. X. Dou, W. K. Yeoh, O. Shcherbakova, D. Wexler, Y. Li, Z. M. Ren, P. Munroe, S. K. Tan, B. A. Glowacki, and J. L. MacManus-Driscoll, Adv. Mater. (Weinheim, Ger.) 18, 785 (2006).

${ }^{13}$ E. Thostenson, Z. Ren, and T. Chou, Compos. Sci. Technol. 61, 1899 (2001).

${ }^{14}$ S. Lee, T. Masui, A. Yamamoto, H. Uchitama, and S. Takama, Physica C 397, 7 (2003).

${ }^{15}$ S. Soltanian, X. L. Wang, J. Horvat, S. X. Dou, M. D. Sumption, M. Bhatia, E. W. Collings, P. Munroe, and M. Tomsic, Supercond. Sci. Technol. 18, 658 (2005).

${ }^{16}$ I. I. Mazin, O. K. Andersen, O. Jepsen, O. V. Dolgov, J. Kortus, A. A. Golubov, A. B. Kuz'menko, and D. van der Marel, Phys. Rev. Lett. 89, 107002 (2002). 